\title{
NOTE ON NAMES AND FILM TITLES
}

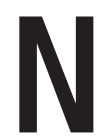

ames are in the Japanese order with family name first. Film titles are a bit problematic, but to the extent possible, the English translation of the title has been provided with the original Japanese title in parenthesis. In cases in which a standard translated title has remained fixed or an official release title exists, that is the title that will be used (e.g., The Life of Oharu for Saikaku ichidai onna). When no official release title and no standard translation exist, an approximation of the Japanese has been used. On occasion, if a film has become famous outside Japan under its original title (e.g., Ikiru), that will be the sole title, although generally an indication of what the title means is provided. In recent years, many Japanese titles have been given in English either written with the alphabet or transliterated phonetically into Japanese. In cases in which an English title but no Japanese title is given, this probably is the case. 
